\title{
A new outbreak of brucellosis in Bulgaria detected in July 2015 - preliminary report
}

R Nenova ${ }^{1}$, I Tomova ${ }^{1}$, R Saparevska ${ }^{2}$, T Kantardjiev ${ }^{1}$

1. National Reference Laboratory High Medical Risk Infections, National Center of Infectious and Parasitic Diseases, Sofia, Bulgaria

2. Surveillance of Communicable Diseases Department, Regional Health Inspectorate -Kyustendil, Bulgaria

Correspondence: Rumiana Nenova (rnenova62@gmail.com)

Citation style for this article:

Nenova R, Tomova I, Saparevska R, Kantardjiev T. A new outbreak of brucellosis in Bulgaria detected in July 2015 - preliminary report. Euro Surveill.

2015;20(39): $\mathrm{pii}=30031$. DOI: http://dx.doi.org/10.2807/1560-7917.ES.2015.20.39.30031

Article submitted on 11 September 2015 / accepted on 01 October 2015 / published on 01 October 2015

During July 2015 a brucellosis outbreak was detected in Kyustendil district, west Bulgaria. As of 15 August, 31 patients have been diagnosed all with an epidemiological connection to Rila town. Patients have not travelled/worked abroad. Breeding family-owned goats and/or improper use of their milk appear to be the main risk factors for transmission of the infection. This second autochthonous brucellosis outbreak in Bulgaria since 2006, affects the western part of the country.

At the beginning of July 2015, a man in his late 30 s presented at the National Reference Laboratory for High Medical Risk Infections (NRL HMRI) in Bulgaria for a consultation and testing in connection with undulant fever up to $38-38.5^{\circ} \mathrm{C}$, that had lasted for ca 30 days. He had had a prior episode of fever starting at the end of April, with an initial empirical antibiotic treatment providing some relief, but soon after the fever had returned, together with myalgia, night sweats and progressive fatigue. The patient resides in Rila town within the Kyustendil district, a district in the west part of the country that has common borders to Serbia and the former Yugoslav Republic of Macedonia (Figure 1). He works as a stock-breeder and declared not consuming milk or milk products of foreign origin. Additionally, he did not report any travel abroad up to one year prior to the onset of symptoms. On the day of the consultation at NRL HMRI, a serum sample from the patient was tested using the Rose Bengal test (BioSystems, Spain) and Brucellacapt (Vircell, Spain), yielding a specific Brucella antibody titre of 1:10,240 (diagnostic titre $\geq 1: 640$ ). Four days later, during a second visit to the laboratory, a blood culture was initiated on Hemoline Performance Diphasic (Biomerieux, France) at $37^{\circ} \mathrm{C}$ with $5 \% \mathrm{CO}_{2}$ and resulted in growth of Brucella spp. on day 10. Based on the serological findings and the clinical presentation, the patient was admitted at the University Infectious Disease Hospital in Sofia for treatment of brucellosis.

\section{Outbreak in Kyustendil district}

Within 24 hours of the diagnosis of the patient, an urgent notification was sent to the Regional Health Inspectorate (RHI), Kyustendil, and the Ministry of Health in accordance with Order 21/2005 for mandatory reportable infectious diseases [1]. Nineteen days after, two other patients, both goat-breeders from the same town as the first patient, were diagnosed with brucellosis. An epidemiological investigation was started immediately in Rila town (2,762 inhabitants). An alert was also sent to the Veterinary Health Service and testing of herds in the area was initiated.

As of 15 August, 31 human infections have been serologically confirmed at the NRL HMRI (Figure 2). Three of the infected persons have professions exposing them to herd animals ( 2 shepherds and 1 veterinarian), 22 are animal owners/breeders and additionally consumed unpasteurised dairy products from their farms, and six consumed unpasteurised local dairy products only. In accordance with the Public Health Law Act [2], all patients with diagnostic titres are referred to the University Infectious Disease Hospital in Sofia for clinical assessment and treatment. Patients are between 25 and 77 years-old (median: 52.7 years). The most affected age group is that between 60 and 69 yearsold ( $n=8$ cases), followed by 30 to 39 year-olds ( $n=6$ cases), two age categories comprising 50 to 59 yearolds and 70 year-olds and over ( $n=5$ cases each), 40 to 49 year-olds ( $n=4$ cases) and 20 to 29 year-olds $(n=3$ cases). In total, five patients are male and 26 female. Twenty-nine persons are Rila town residents. Two reside outside of the town but visited it or were in its vicinity less than one month prior to illness onset. Of these, one is from another district than Kyustendil, but went to see relatives in Rila town; the other is from a neighbouring city within Kyustendil district, but worked as a veterinarian in an area near the town. 
Map showing districts previously (Haskovo) and presently (Kyustendil) affected by autochthonous human brucellosis outbreaks, Bulgaria, 2006-2015

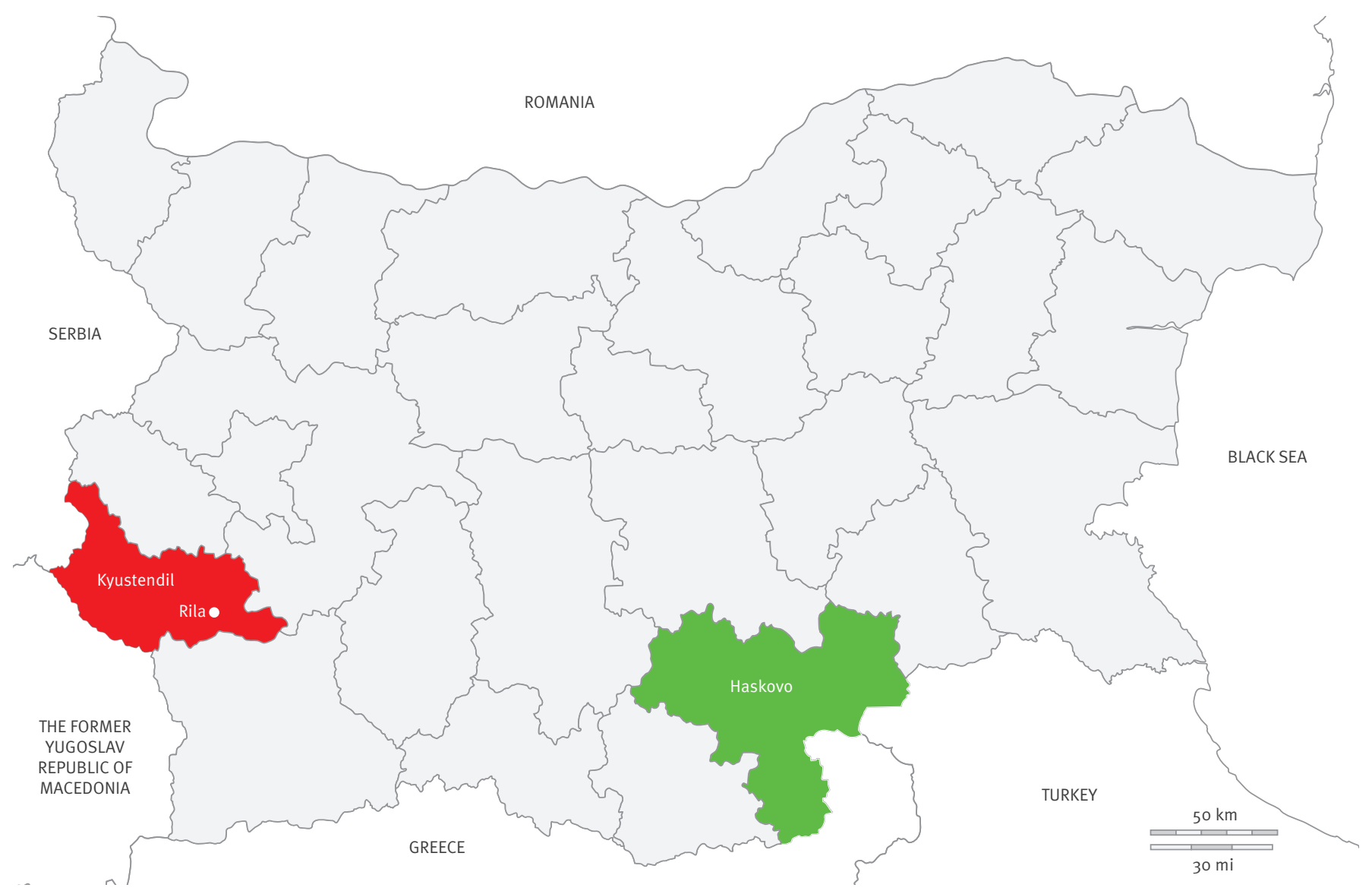

Haskovo district, in green, was the most affected area during a 2006 to 2008 outbreak of brucellosis. Kyustendil district, in red, is where the current 2015 outbreak is still ongoing. All patients in this outbreak have a connection to Rila town, which is also indicated.

\section{Brucellosis in Bulgaria}

Brucellosis caused by $B$. melitensis is a widespread zoonosis that can affect every organ and system of the human body [3]. Transmission to humans can occur via direct contact with infected animals and/or consumption of contaminated unpasteurised milk and dairy products. The disease is endemic in many parts of the world, particularly in some areas of the Mediterranean region close to Bulgaria [4]. Despite this, for several decades up to 2006, no autochthonous human brucellosis cases were notified in Bulgaria. In this period, only one outbreak occurred in the country in 2005, but results of a detailed epidemiological investigation revealed that all human cases had been imported [5].

Primary and confirmatory diagnosis of brucellosis in Bulgaria is performed by the NRL HMRI at the National Center of Infectious and Parasitic Diseases, together with the diagnosis of other dangerous infections such as anthrax, glanders, melioidosis, plague, and tularaemia.

In 2006, seven human cases were microbiologically confirmed in the country, all without any epidemiological data pointing to importation. These patients marked the beginning of an autochthonous outbreak in the south of Bulgaria, with Haskovo district (Figure 1) constituting the most affected area. Epizootiological investigations revealed that the cause of this outbreak was illegal importation of infected animals from a neighbouring endemic country. As a result, by the end of 2008, 71 persons had been infected and more than 600 animals had to be destroyed.

Brucellosis control for herds in Bulgaria is based on the 'test and slaughter' approach. Together with efforts of the Human Public Health authorities, this policy led to a significant reduction in the number of human cases after 2008 [6]. Since 2010, the number of epidemiologically unrelated infections reported annually among Bulgarian residents ranges between zero and two (data not shown).

Based on regular serological testing performed by the Veterinary Health Service, the last having occurred in October 2014, animal herds in the Kyustendil district were considered brucellosis-free up to the current human outbreak. After its detection, serological testing 


\section{FIGURE 2}

Distribution of numbers of brucellosis human cases according to date of diagnosis, ongoing outbreak of brucellosis, Kyustendil district, Bulgaria, 2015 ( $\mathrm{n}=31$ cases)

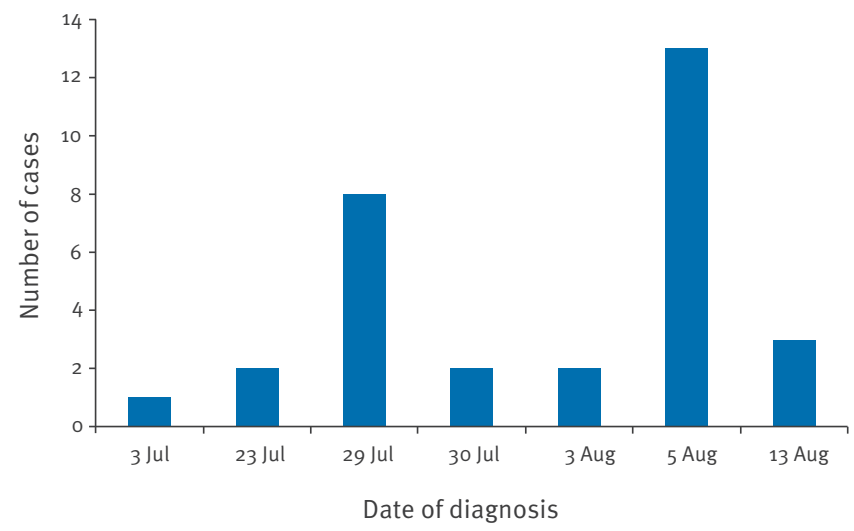

of the animals was resumed, and as of 15 August, 97 of 2,245 tested animals were found positive. For more than five decades before the current outbreak, no autochthonous human cases had occurred in this area. Registers point only to one patient, diagnosed in 2006 , whereby according to results of an epidemiological investigation, infection most probably occurred when working at a dairy farm in Italy (data not shown).

\section{Epidemiological investigation in Kyustendil district and control measures}

Active epidemiological investigation of the current outbreak in Kyustendil not only unveiled new cases of the disease, but also revealed that raw milk stored at ambient temperature, which in July this year was above $30^{\circ} \mathrm{C}$ (http://www.meteo.bg/), was frequently consumed by local residents. Based on preliminary descriptive epidemiological findings, breeding of family goats and/or consumption of unboiled milk and homemade soft cheese appear as potential risk factors for transmission of the infection. Some of the patients have no goats but consumed milk and dairy products supplied from friends with small-scale farms. RHI has spread information (through media and leaflets) about the dangerous nature of the disease, mechanisms of transmission, clinical manifestations and the necessary preventive measures, including the recommendation to boil milk for at least 10 min before consumption. During the active surveillance, door-to-door visits have been made not only to ensure the distribution of this information, but also to seize and destroy all improperly homemade and/or stored dairy products. Until further notice, a ban on the use of domestic milk or milk products, such as soft cheese and butter, as well as uncontrolled slaughtering of animals is imposed. According to data from the Bulgarian Food Safety Agency, dairy products available in markets comply with the European regulations of hygiene and safety.

\section{Epizootiological measures}

Animal movement is prohibited. Serological testing of small ruminants and cattle for brucellosis is still ongoing in the area. Animals testing positive are subjected to euthanasia and destruction. Animal owners will receive compensation according to the Law of Veterinary Activity. The affected farms, all of them family owned, have been disinfected with Sanofit $1 \%$ (Ukrzoovet). The source of infection for the animals and their movement prior the outbreak discovery is under investigation.

\section{Discussion and conclusion}

Although the brucellosis outbreak in Kyustendil is still ongoing, the aim of the current report is to highlight its onset. At time of writing, the field investigation is still under way and information on cases occurring after mid-August 2015 is not yet fully complete/available. On the basis of the past history of Kyustendil district as a brucellosis-free area, and the epizootiological situation in the rest of Bulgaria, the current outbreak is most probably a consequence of unauthorised import of infected animals from endemic country/ies. That infected animals in this outbreak were imported from Haskovo district, which was the last previous area with a brucellosis outbreak in Bulgaria is unlikely, as animals in Haskovo district have been regularly tested for Brucella since 2008 and to date none have been found positive. Animals from Kyustendil were not likely exposed to contaminated pastures in the vicinity of endemic countries either, as Rila town and its surrounding pastures lie ca $80 \mathrm{~km}$ away from the border with the former Yugoslav Republic of Macedonia and ca $140 \mathrm{~km}$ from that with Serbia. Uncontrolled movement of animals to/through the borders is moreover prohibited and, according to data from the National Veterinary Health Service no herds positive for brucellosis have been so far detected along the border. Typing and sequencing of Brucella isolates is currently under way and may provide more clues as to the source of the outbreak in the future.

As it is well known, prevention of human brucellosis depends on the control of the disease in animals. Ovine/caprine brucellosis has been eliminated in Bulgaria since 1941 and bovine brucellosis since 1958 [7]. As a result, prior to 2006 , there had not been any autochthonous human cases in the country for decades. The current outbreak, as well as the previous one (2006-2008), give grounds to pay particular attention to two important points, namely: (i) the occurrence of positive animals in brucellosis-free regions stress on the need for more stringent measures with regard to uncontrolled trade/migration of animals, especially in regions bordering enzootic countries; (ii) the underestimation of the importance of applying preventive measures in local family-owned farms appears to be the main risk factor for brucellosis among Bulgarian residents. More joint efforts are needed from the responsible public health and veterinary authorities to solve these problems. Brucellosis remains a 
serious challenge for many of the countries surrounding Bulgaria [8]. Without rapid implementation and continuous compliance with the appropriate measures we could expect a more frequent re-emergence of this zoonosis in the country.

\section{Acknowledgements}

The authors would like to express their gratitude to Gatanka Risova, NRL HMRI for her excellent technical assistance, to Iliana Krasteva, RHI-Kystendil, for the logistic help during the epidemiological investigation and to all clinical infectious disease specialists, taking further care of the patients.

\section{Conflict of interest}

None declared.

\section{Authors' contributions}

RN and IT: laboratory testing and notification of the results, interpretation of the microbiological and epidemiological data, writing and editing the manuscript; RS: epidemiological investigation and sampling; TK: supporting the whole investigation and reviewing the final version.

\section{References}

1. [Order No 21/2005 for notification, registration and reporting of communicable diseases]. Ministry of Health, Official Bulletin 15, 2005. Bulgarian.

2. Public Health Law Act. Bulgarian. Available from: http://www. zdrave.net/document/institute/week_theme/23062003/ zoz ms-suglasuvane.

3. PappasG, AkritidisN, BosilkovskiM, TsianosE. Brucellosis.N Engl J Med. 2005;352(22):2325-36. DOI: 10.1056/NEJMra050570 PMID: 15930423

4. European Food Safety Authority and European Centre for Disease Prevention and Control (EFSA and ECDC). The European Union Summary Report on Trends and Sources of Zoonoses, Zoonotic Agents and Food-borne Outbreaks in 2012. EFSA Journal 2014;12(2):3547. Available from: http://www.efsa. europa.eu/sites/default/files/scientific_output/files/main_ documents/3547.pdf

5. Likov B, Nenova R, Tomova I, Kamenov P, Boikovski I, Rubenova M, Tsankova S, Kantardjiev T. Epizootical and epidemiological features of Brucellosis in sheep and goats (Brucella melitensis) in Bulgaria for the period 2005-2008. Contributions Sec Biol Med Sci. 2010; XXXI(1),:55-64.

6. Nenova R, Tomova I, Ivanov I, Stoeva M. Human cases of anthrax, tularemia and brucellosis in Bulgaria for the past decade. Poster presented at the Fifth Congress of Macedonian Microbiologists; 2014 May 28-31; Ohrid, Macedonia. A50, 120.

7. CorbelMJ. Brucellosis: an overview.Emerg Infect Dis. 1997;3(2):213-21. DOI: 10.3201/eido302.970219 PMID: 9204307

8. Donev D, Karadzovski Z, Kasapinov B, Lazarevik V. Epidemiological and public health aspects of brucellosis in the Republic of Macedonia. Contributions Sec Biol Med Sci. 2010; XXXI(1): 33-54. 